24-25 de agosto de 2006

\title{
Conferencia Internacional «El uso y transformación del espacio en América precolonial: hacia comprensiones sociales»
}

24-25 de agosto de 2006

Marina Romero, Claudia Arce y Claudio Cesar Olaya

\section{(2) OpenEdition}

Journals

Edición electrónica

URL: http://journals.openedition.org/bifea/4708

DOI: $10.4000 /$ bifea.4708

ISSN: 2076-5827

Editor

Institut Français d'Études Andines

Edición impresa

Fecha de publicación: 1 mayo 2006

Paginación: 233-234

ISSN: 0303-7495

\section{Referencia electrónica}

Marina Romero, Claudia Arce y Claudio Cesar Olaya, « Conferencia Internacional «El uso y

transformación del espacio en América precolonial: hacia comprensiones sociales» », Bulletin de I'Institut français d'études andines [En línea], 35 (2) | 2006, Publicado el 08 mayo 2006, consultado el 15 diciembre 2020. URL : http://journals.openedition.org/bifea/4708 ; DOI : https://doi.org/10.4000/bifea. 4708

\section{(c)}

Les contenus du Bulletin de l'Institut français d'études andines sont mis à disposition selon les termes de la licence Creative Commons Attribution - Pas d'Utilisation Commerciale - Pas de Modification 4.0 International. 


\section{4-25 de agosto de 2006}

En la ciudad de Lima (Perú), teniendo como sede los auditorios de la Alianza Francesa de Lima y del Museo Nacional de Arqueología, Antropología e Historia del Perú (MNAAHP), se llevó a cabo la conferencia anual denominada Seminario de Arqueología UNFV, la cual en su quinta edición llevó como título El uso y transformación del espacio en América precolonial: hacia comprensiones sociales. Este evento fue organizado por Marina Romero y Claudia Arce, estudiantes de la especialidad de Arqueología de la Universidad Nacional Federico Villarreal, en colaboración con el IFEA, el MNAAHP y el boletín Corriente Arqueológica, este último dirigido por los suscritos. Esta conferencia reunió a especialistas de proyectos e instituciones de Argentina, Chile, Estados Unidos, Korea del Sur, España, Bélgica y Perú.

El objetivo principal del evento fue demostrar cómo en la arqueología el término «espacio» puede llegar a tener una gran diversidad de significados y concepciones teóricas, debido a la ambigüedad y amplitud del término. Se presentaron trabajos que cubrían diferentes campos de investigación y perspectivas, como la distribución espacial de asentamientos, componentes arquitectónicos, paisajes, áreas domésticas (Household), definición y diferenciación de funcionalidades, sacralización de espacios geográficos, urbanismo, espacios políticos y territorialidad. Así también, fue otro de los objetivos exponer casos que no se limiten solo al área de los Andes Centrales, razón por la cual se contaron con ponencias que exponen estudios en las áreas del norte y centro de Chile, de la Región Pampeana, Tucumán y norte y oeste de la República Argentina, y con una ponencia para el área de Colombia. Uno de los aspectos más fructíferos fue el de tener casos comparativos para poder conocer trabajos en áreas que, lamentablemente, son poco familiares para los arqueólogos que trabajan en el área central andina. Los colegas chilenos y argentinos manejan perspectivas que pueden ser convergentes o divergentes en muchos puntos y enfoques si las comparamos con los casos de estudios para el área peruana. Fue muy reconfortante para el público y los organizadores poder observar resultados de estudios de áreas relativamente alejadas, y acceder a información que en su mayoría es original. 
El evento permitió al público asistente apreciar la complejidad de diversas situaciones sociales acaecidas en las áreas sudamericanas presentadas antes de la irrupción europea, desde la perspectiva del estudio de los espacios físicos, políticos y sociales. Este público se conformó tanto por estudiantes como por profesionales, constituyendo una aceptable asistencia a pesar de la avalancha de eventos previos y próximos especializados en arqueología llevados a cabo en Lima y otras ciudades del Perú.

Debido a la diversidad de enfoques y temas derivados del sugerente título de la conferencia, se descartó el realizar una plenaria o mesa de trabajo final, en la cual se discutan conclusiones, pues en esta ocasión se ha dejado de lado el enfoque estrictamente monotemático del evento, para dar paso a algo más versátil y variado. Esto también se verá plasmado cuando se publiquen las actas del evento en el tercer número de Corriente Arqueológica, el cual debe ser presentado en el mes de Noviembre de 2007. El segundo número se encuentra actualmente en prensa y debe ser presentado en noviembre de 2006.

Marina ROMERO, Claudia ARCE, Claudio César OLAYA 